\title{
Far ultraviolet airglow remote sensing measurements on Feng Yun 3D meteorological satellite
}

Yungang Wang ${ }^{1,2}$, Liping $\mathrm{Fu}^{3}$, Fang Jiang ${ }^{3}$, Xiuqing Hu${ }^{1}$, Chengbao Liu ${ }^{1}$, Xiaoxin Zhang ${ }^{1,2}$, Jiawei $\mathrm{Li}^{1,2}$, Zhipeng Ren ${ }^{4}$, Fei He ${ }^{4}$, Lingfeng Sun ${ }^{4}$, Ling Sun ${ }^{1}$, Zhongdong Yang ${ }^{1}$, Peng Zhang ${ }^{1}$,

5 Jingsong Wang ${ }^{1,2}$, Tian Mao ${ }^{1,2}$

1 National Satellite Meteorological Center, Chinese Meteorological Administration, Beijing, China

2 Key Laboratory of Space Weather, National Center for Space Weather, Chinese Meteorological Administration, Beijing, China

3 National Space Science Center, Chinese Academy of Sciences, Beijing, China

104 Key Laboratory of Earth and Planetary Physics, Institute of Geology and Geophysics, Chinese Academy of Sciences, Beijing, China

Correspondence to: Tian Mao (email: maotian@cma.cn)

\begin{abstract}
The Ionospheric Photometer (IPM) is carried on the Feng Yun 3D (FY3D) meteorological satellite, which allows for the measurement of far-ultraviolet (FUV) airglow radiation in the thermosphere. IPM is a compact and high-sensitivity nadir-viewing FUV remote sensing instrument. It monitors $135.6 \mathrm{~nm}$ emission in the night-side thermosphere and $135.6 \mathrm{~nm}$ and $\mathrm{N}_{2} \mathrm{LBH}$ emissions in the day-side thermosphere that can be used to invert the peak electron density of the F2 layer $\left(\mathrm{NmF}_{2}\right)$ at night and $\mathrm{O} / \mathrm{N}_{2}$ ratio in the daytime, respectively. Preliminary observations show that the IPM could monitor the global structure of the equatorial ionization anomaly (EIA) structure around 2:00 local time using OI 135.6 nm nightglow properly. It could also identify the reduction of $\mathrm{O} / \mathrm{N}_{2}$ in the high-latitude region during the geomagnetic storm of Aug. 26,

20 2018. The IPM derived $\mathrm{NmF}_{2}$ accords well with that observed by 4 ionosonde stations along $120^{\circ} \mathrm{E}$ with a standard deviation of $26.67 \%$. Initial results demonstrate that the performance of IPM meets the designed requirement and therefore can be used to study the thermosphere and ionosphere in the future.
\end{abstract}

\section{Introduction}

The Earth's far-ultraviolet (FUV) airglow radiation from the thermosphere includes the emission of $\mathrm{H}, \mathrm{O}$, and $\mathrm{N}_{2}$ and the absorption of $\mathrm{O}_{2}$ (Meier, 1991). The OI $135.6 \mathrm{~nm}$ nightglow emission, which is mainly produced by the recombination of ionospheric $\mathrm{O}^{+}$and electron, can present spatial and temporal variations of the ionosphere in the nighttime. The $135.6 \mathrm{~nm}$ and $\mathrm{N}_{2} \mathrm{LBH}$ dayglow emission, which are produced by energetic photon-electron impact excitation of the neutral atmosphere, 
are used to derive the characteristics of column $\mathrm{O} / \mathrm{N}_{2}$ in the sunlit disk. The FUV radiation can be completely absorbed by the lower atmosphere, and the Earth's atmosphere is opaque to the FUV radiation. The background emission of FUV airglow from the Earth's surface is absent. So FUV airglow radiation is particularly well-suited to space-based remote sensing (Paxton et al., 2003; Budzien et al., 2019). In past decades, FUV spectrography based on satellites has been used extensively in studying the thermosphere and ionosphere, such as, GUVI (the Global Ultra-Violet Imager) on the NASA TIMED (Thermosphere, Ionosphere, Mesosphere Energetics and Dynamics) satellite (Christensen et al., 2003), and the Far Ultraviolet Imager (FUV) on the NASA IMAGE (Imager for Magnetopause-to-Aurora Global Exploration) satellite (Sagawa

35 et al., 2005). The other useful equipment used in studying the thermosphere and ionosphere is ionospheric photometer, which is compact and high-sensitive. The U.S. Naval Research Laboratory firstly gave the concept for a new class of ionospheric photometer twenty years ago. It was supplied in the Tiny Ionospheric Photometer (TIP) on the Constellation Observing System for Meteorology, Ionosphere, and Climate satellites (Anthes et al., 2008; Dymond et al., 2016), complemented and upgraded in the Tiny Ionospheric Photometer (TIP) as part of the GPS Radio Occultation and Ultralviolet

40 Photometry -Colocated (GROUP-C) experience on the International Space Station (Budzien et al., 2019; Budzien et al., 2017), and notably improved in the Triple Tiny Ionospheric Photometer (Tri-TIP) in Coordinated Ionospheric Reconstruction CubeSat Experience (Dymond et al., 2017; Stephan et al., 2018).

The compact and high-sensitivity nadir-viewing FUV Ionospheric Photometer (IMP) is one of ten scientific payloads aboard the Feng Yun 3D meteorological satellite. IPM monitors $135.6 \mathrm{~nm}$ emission in the night-side thermosphere and $135.6 \mathrm{~nm}$ and $\mathrm{N}_{2}$ LBH emissions in the day-side thermosphere by employing a filter wheel that adds two red-leak signal channels for daytime and nighttime red-leak respectively. Red-leak refers to weak residual sensitivity of the sensor to detect unwanted wavelengths including visible light that is "redder" than ultraviolet (Budzien et al., 2019). The main scientific objectives of IPM are follows: (1) Measure $135.6 \mathrm{~nm}$ emission in the night-side thermosphere to capture the large-scale structure of the low- and mid-latitude ionosphere. (2) Measure $135.6 \mathrm{~nm}$ and $\mathrm{N}_{2} \mathrm{LBH}$ emissions in the day-side thermosphere to capture global variations $\mathrm{O} / \mathrm{N}_{2}$ ratio and evolutions of the thermosphere and ionosphere during extreme space weather events. The FY3D is an afternoon sun-synchronous satellite with an orbit altitude of $830 \mathrm{~km}$, an inclination of $98.75^{\circ}$ and orbit period of 102 minutes, and designed for weather forecast, atmospheric chemistry, climate change monitoring, and space weather monitoring. The FY3D satellite was launched at 18:35 UTC on November 14, 2017 from the Taiyuan Satellite Base, Shanxi province, China. This paper presents instrumental descriptions and initial observations by IPM.

\section{Instrument Description}

\subsection{Instrument parameters requirements}

According to the two main scientific objectives mentioned above, the IPM instrument parameters requirements are summarized in the Table1. In the design of the ionospheric photometer, there are two important problems to be solved. One problem is red-leak. It is a major challenge to ionospheric photometer that visible light radiation from the sun is about 109 
https://doi.org/10.5194/amt-2021-195

Preprint. Discussion started: 30 September 2021

(c) Author(s) 2021. CC BY 4.0 License.
Atmospheric

Measurement

Techniques

Discussions

60 times more than FUV radiation. The other problem is that ionospheric photometers need to eliminate $130.44 \mathrm{~nm}$ and shorter wavelengths airglow and collect $135.6 \mathrm{~nm}$ airglow emission with high sensitivity.

Table 1. FY-3D IPM instrument parameters requirements.

\begin{tabular}{cl}
\hline Parameter & value \\
\hline Wavelength & $135.6 \mathrm{~nm}$ (night mode $)$ \\
& $135.6 \mathrm{~nm}$ and $145-180 \mathrm{~nm}$ (day mode) \\
Field of View & $\sim 3.5^{\circ}$ (along orbit) $\times 1.6^{\circ}$ (cross orbit) \\
Sensitivity & day mode: $\geq 1$ counts/s/Rayleigh@ $135.6 \mathrm{~nm}$ \\
& night mode: $\geq 150$ counts/s/Rayleigh@ $135.6 \mathrm{~nm}$ \\
Spatial resolution & $\sim 30 \mathrm{~km} @$ ionosphere $(300 \mathrm{~km})$ \\
Time resolution & $2 \mathrm{~s}$ (day mode $)$ \\
& $10 \mathrm{~s}$ (night mode ) \\
\hline
\end{tabular}

\subsection{Composition, channel, and mode}

(a) IPM instrument

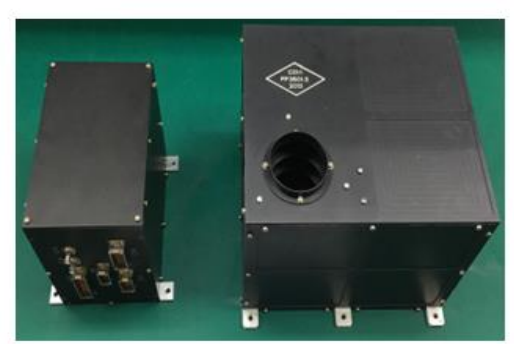

(b) Optical system

65
Discussions 


\section{Figure 1: IPM instrument.}

The IPM instrument is shown in Fig. 1 and includes a telescope, a filter wheel, a detector system, and control electronics cabinet. The telescope has a field-of-view of $3.5^{\circ}$ (along orbit) $\times 1.6^{\circ}$ (cross orbit). An off-axis aluminum mirror coating $\mathrm{MgF}_{2}$ is used to collected airglow emission in the telescope. To suppress the longer wavelength radiance, a sunblind PMT (R10825, Hamamatsu) with CsI photocathode is used in the detector system (Fu et al, 2015). The quantum efficiency of the PMT with an effective area of $4 \times 9.5 \mathrm{~mm}$, is about $26 \%$ at the wavelength $135.6 \mathrm{~nm}, 6.17 \times 10^{-5}$ at $254 \mathrm{~nm}$, and $4.06 \times 10^{-8}$ at $514 \mathrm{~nm}$. The PMT has better than $10^{-4}$ rejection at wavelengths longer than $200 \mathrm{~nm}$.

75 IPM monitors $135.6 \mathrm{~nm}$ emissions in the nighttime and $135.6 \mathrm{~nm}$ and $\mathrm{N}_{2} \mathrm{LBH}$ emissions in the daytime by employing a filter wheel. There are six spots in the filter wheel (Fig. 1 (c)) corresponding to six channels of IPM: dark count channel, $135.6 \mathrm{~nm}$ nightside channel, red-leak nightside channel, red-leak dayside channel, $\mathrm{N}_{2} \mathrm{LBH}$ dayside channel, and $135.6 \mathrm{~nm}$ dayside channel. The Channel information of IPM is shown in Table 2. In order to suppress the longer wavelength radiance further, the band-pass filter centred on $135.6 \mathrm{~nm}$ is used in the $135.6 \mathrm{~nm}$ dayside channel, and the band-pass filter centred on $160 \mathrm{~nm}$ is used in the $\mathrm{N}_{2} \mathrm{LBH}$ channel. Besides, IPM specifically adds two red-leak signal channels for daytime and nighttime redleak respectively. Based on the design of dayside or nightside channel, a $\mathrm{SiO}_{2}$ filter is added in red-leak channels in order to eliminate below $180 \mathrm{~nm}$ wavelength airglow. By differencing the measurements of dayglow channels and red-leak dayside channel, dayglow radiations can be detected. And by differencing the measurements of $135.6 \mathrm{~nm}$ nightside channel and redleak nightside channel, $135.6 \mathrm{~nm}$ radiation in the nighttime can be detected. To exclude radiation shorter than $135.6 \mathrm{~nm}$ completely, a $0.5 \mathrm{~mm}$-thin VUV-grade BaF2 flat filter is used and the transmittance at $135.6 \mathrm{~nm}$ at room temperature is 0.5 (Fu et al., 2015). The emission of wavelengths shorter than $132 \mathrm{~nm}$ cannot pass the $0.5 \mathrm{~mm}$-thick $\mathrm{BaF}_{2}$ filter over a temperature range of $5{ }^{\circ} \mathrm{C}$ to $35^{\circ} \mathrm{C}$.

Table2. Channel information.

\begin{tabular}{lll}
\hline Number & Name & Filter \\
\hline 1 & dark count channel & none \\
2 & 135.6nm dayside channel & BaF2+bandpass \\
3 & N2LBH dayside channel & BaF2+bandpass \\
4 & red-leak dayside channel & BaF2+bandpass+quartz \\
5 & red-leak nightside channel & BaF2+quartz \\
6 & 135.6nm nightside channel & BaF2 \\
\hline
\end{tabular}

IPM has two observation modes: day mode and night mode. The day mode includes 4 times observation of the $135.6 \mathrm{~nm}$ dayside channel, 4 times observation of the $\mathrm{N}_{2} \mathrm{LBH}$ channel, 2 times observation of the red-leak dayside channel, and 1 dark 
count observation in each frame. The night mode includes 8 times observation of the $135.6 \mathrm{~nm}$ night channel, 1 observation of the red-leak nightside channel, and 1 dark count observation.

\subsection{Laboratory Calibration}

The IPM was calibrated in ground laboratory prior to flight. The optical calibration facility in the ground laboratory has a deuterium lamp, a monochromator, a collimator, a diffuser board, and a NIST standard detector assembled in a modular pattern. The deuterium lamp (L11798) with a $\mathrm{MgF}_{2}$ window has $150 \mathrm{~W}$ power and provides a bright, stable source of FUV radiation. The source of FUV radiation is wavelength-selected by the monochromator (234/302) which has a $f / 4.50 .2 \mathrm{~m}$ Czerny-Turner with a 1200 grooves/mm grating. A collimator ensures that the beam consists of parallel rays. The NIST standard detector (AXUV-100G) provides a reference for calibrating IPM. The entire facility is installed in a vacuum environment which allows the propagation of radiation in the far ultraviolet.

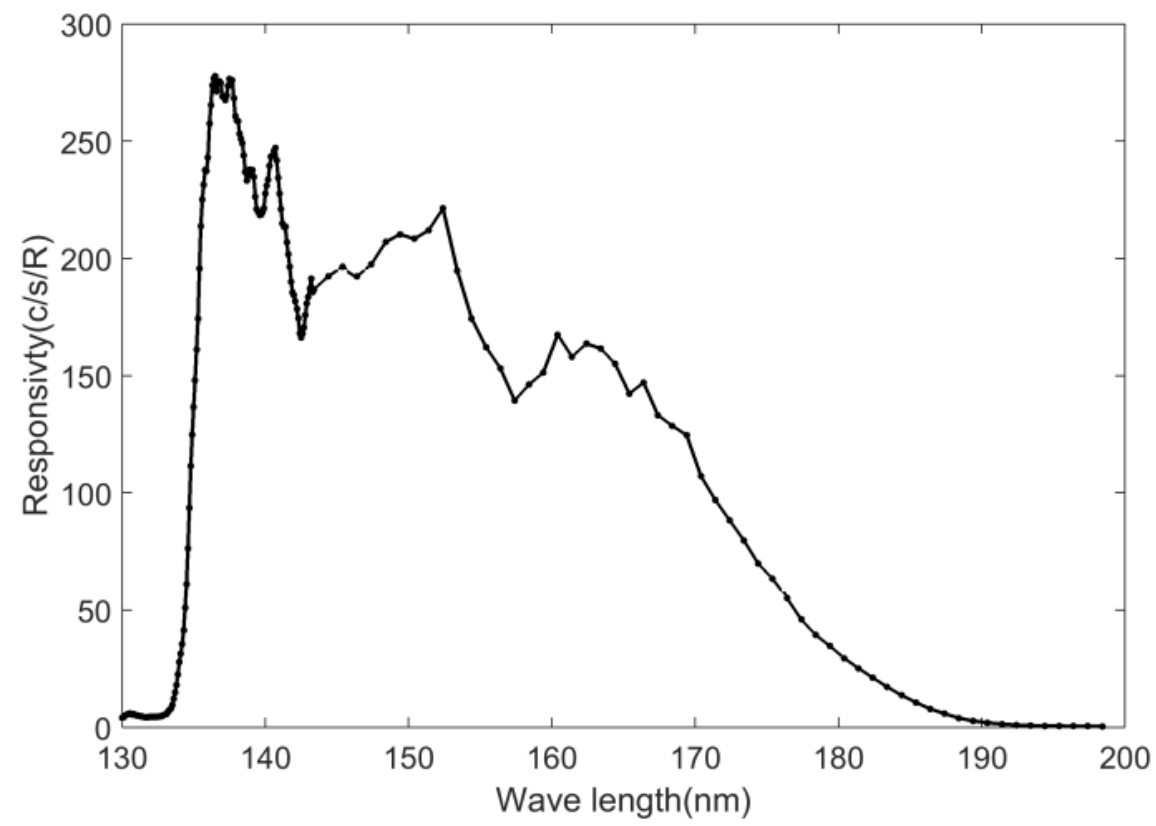

Figure 2: The IPM responsivity of the $135.6 \mathrm{~nm}$ nightside channel in counts/s/R.

105

The processes of calibration are following: First, the FUV light at 125-200 nm from a deuterium lamp is selected by the monochromator. Second, the wavelength-selected light reaches the NIST standard detector through the collimator, and the NIST standard detector obtains the irradiance of the wavelength-selected light. And then, by using a rotating platform, the wavelength-selected light reaches the diffuser board through the collimator and enters IPM. IPM obtains the count of the wavelength-selected light. Finally, the count and irradiance of the wavelength-selected light are used in calculating the responsivity to the wavelength-selected light. The uncertainty of the ground calibration comes from the stability of the FUV 
light source, the error of the standard detector, the bi-directional reflection distribution function (BRDF) uncertainty of the diffuser board, the non-uniformity of the light source, and so on. The uncertainty of the ground calibration is estimated to reach $11.25 \%$. As a function of wavelength, the responsivity of the $135.6 \mathrm{~nm}$ nightside channel from 130 to $200 \mathrm{~nm}$ is shown

115 in Figure 2. The responsivity to $135.6 \mathrm{~nm}$ radiation at night is about 266.9 counts/s/R near the peak of the responsivity function distribution, and reaches the design requirement of the $135.6 \mathrm{~nm}$ nightside channel. The responsivity to $135.6 \mathrm{~nm}$ radiation at night provides high sensitivity in observations of OI $135.6 \mathrm{~nm}$ radiation at night.

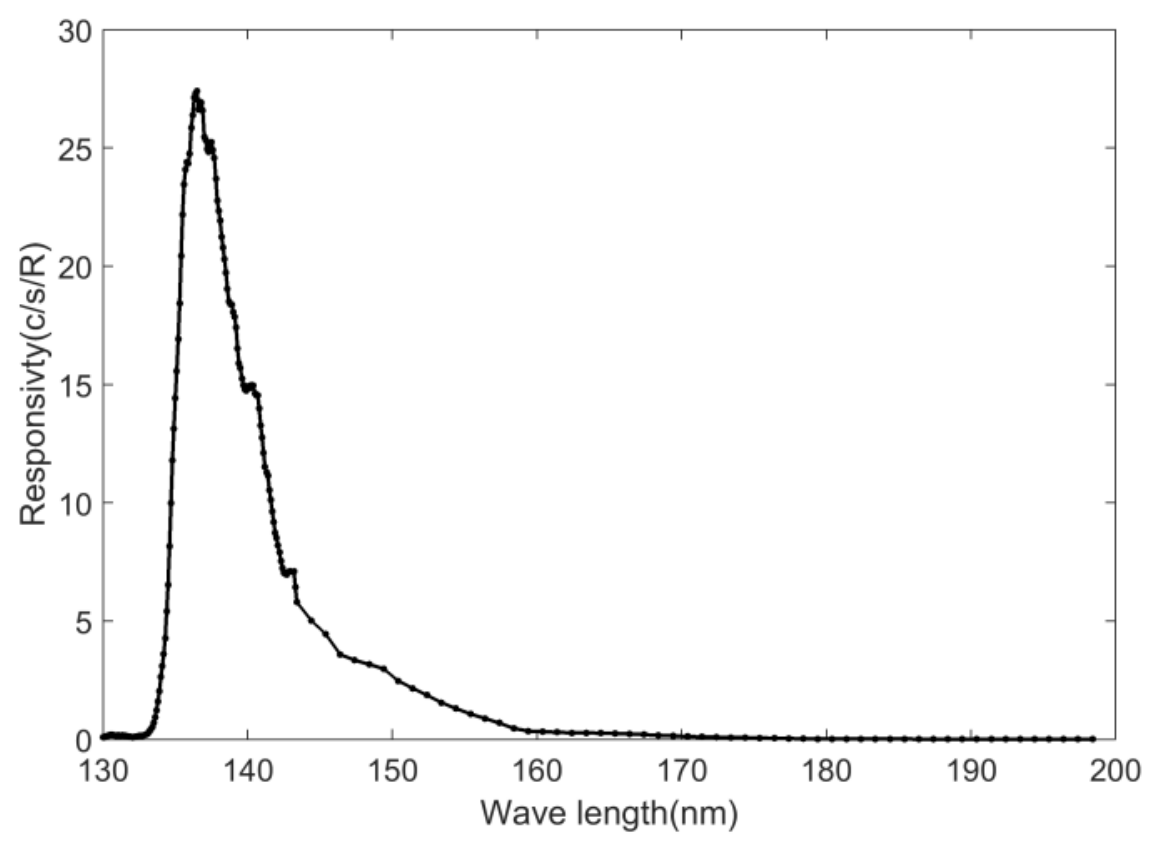

Figure 3: The IPM responsivity of the $135.6 \mathrm{~nm}$ dayside channel in counts/s/R.

As a function of wavelength, the responsivity of the $135.6 \mathrm{~nm}$ dayside channel from $130 \mathrm{~nm}$ to $200 \mathrm{~nm}$ is shown in Figure 3. The responsivity to the $135.6 \mathrm{~nm}$ radiation in daytime is about 23.20 counts/s/R, and also reaches the design requirement of the $135.6 \mathrm{~nm}$ dayside channel. The responsivity is much less than the one on the nightside due to the bandpass used in the $125135.6 \mathrm{~nm}$ dayside channel, which is designed to obtain the radiation of $135.6 \mathrm{~nm}$ in daytime and suppress the radiation at wavelengths shorter than $135.6 \mathrm{~nm}, \mathrm{~N}_{2} \mathrm{LBH}$ and red-leak in daytime. The other bandpass is used in the $\mathrm{N}_{2} \mathrm{LBH}$ day channel in order to obtain the radiation of $\mathrm{N}_{2} \mathrm{LBH}$ and suppress the radiation of $135.6 \mathrm{~nm}$ and red-leak in daytime. The responsivity of $\mathrm{N}_{2} \mathrm{LBH}$ channel is shown in Figure 4. 


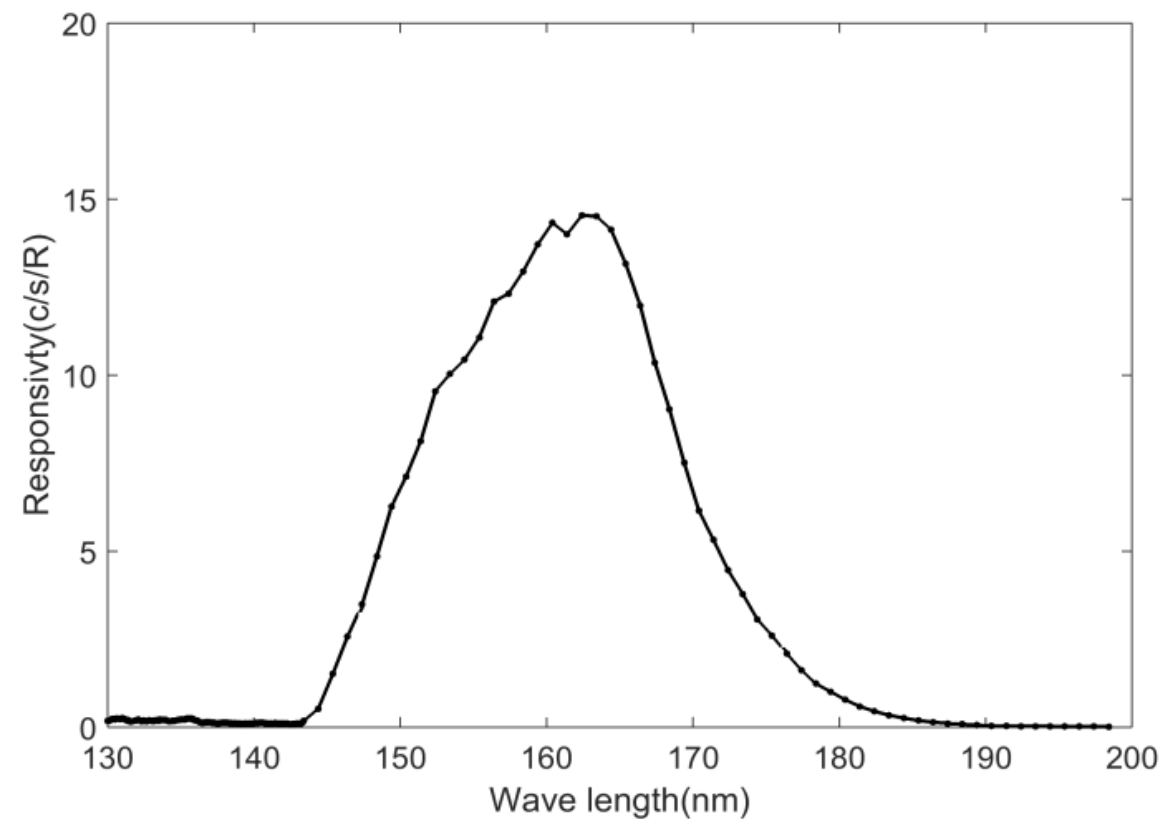

Figure 4: The IPM responsivity of the $\mathrm{N}_{2} \mathrm{LBH}$ channel in counts/s/R.

\section{Observation Results}

\subsection{OI $135.6 \mathrm{~nm}$ emission on the nightside}

135 After the FY3D satellite was launched at 18:35 UTC on November 14, 2017, IPM started operation at 10:20 UTC on November 25, 2017. In IPM data processing, dark count is used to confirm the working status of IPM. Generally, the dark count of IPM is less than 10 counts. When the FY3D satellite passes by the South Atlantic Anomaly (SAA), the dark count of IPM increases rapidly and reaches a peak about 2000 counts due to the high energetic particles over the SAA. 

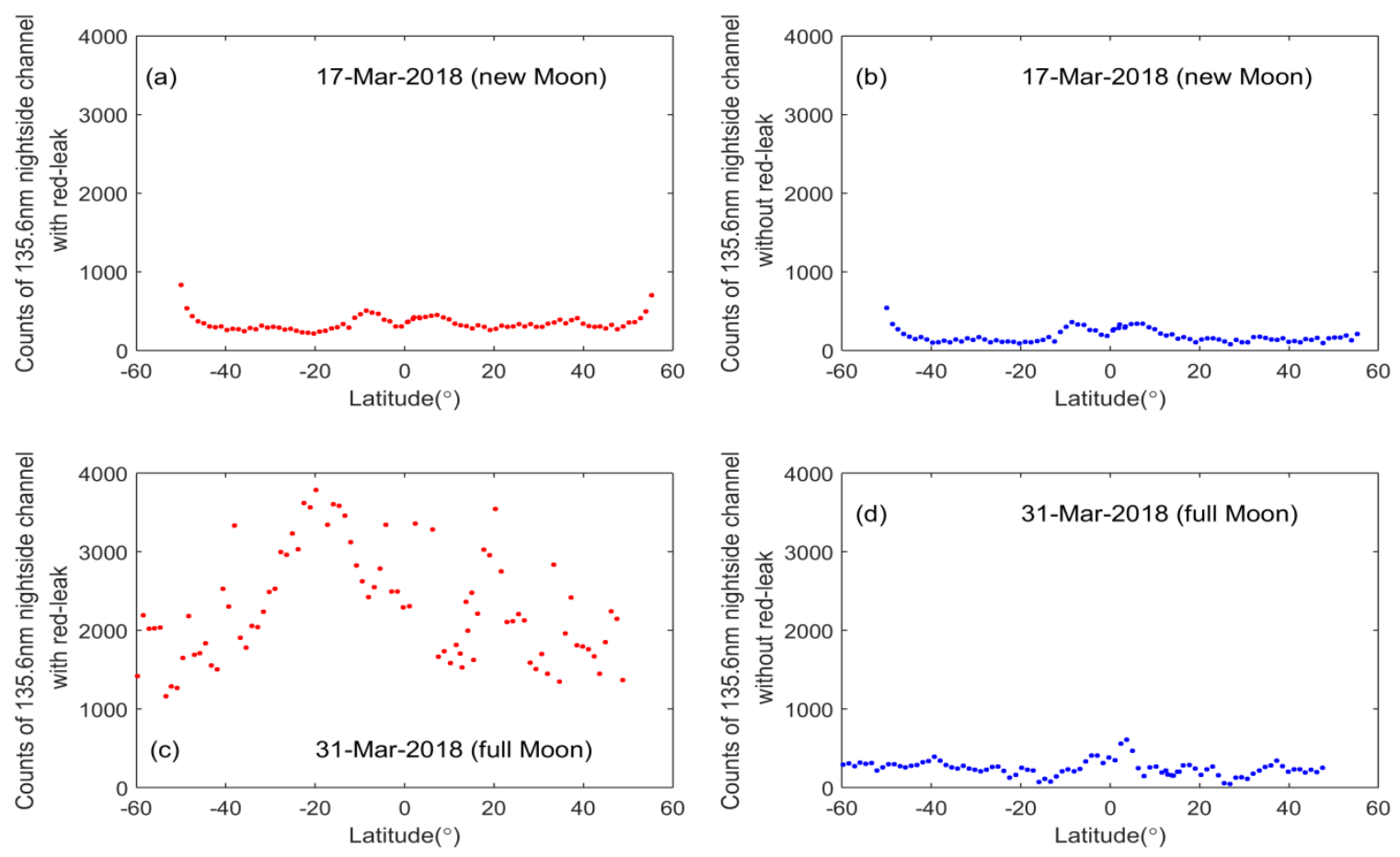

140

Figure 5: The count of the $135.6 \mathrm{~nm}$ nightside channel with (left) and without (right) red-leak for new Moon (top) and full Moon (bottom) situation, respectively. March 17, 2018 is new Moon day, and March 31, 2018 is full Moon day.

The count of the $135.6 \mathrm{~nm}$ nightside channel is presented in Fig. 5. The count with red-leak on March 17, 2018 (new Moon)

145 and on March 31, 2018 (full Moon) are shown in (a) and (c), respectively. The count without red-leak on March 17, 2018 and March 3, 2018 are shown in (b) and (d), respectively, which deducted the count of red-leak. The count of the $135.6 \mathrm{~nm}$ nightside channel in (c) is several times the count of the $135.6 \mathrm{~nm}$ nightside channel in (a) due to moonlight reflecting into the $135.6 \mathrm{~nm}$ nightside channel from cloud tops, while the count levels in (b) and (d) are very similar. We found that the redleak nightside channel is effective to deduct the contamination of moonlight on the $135.6 \mathrm{~nm}$ nightside channel.

150 The example of the global count of the $135.6 \mathrm{~nm}$ nightside channel is presented in Fig. 6 (a). The red solid line indicates the magnetic dip equator. The data in Fig. 6 are from 7 to 11 December 2017. From 7 to 11 December 2017, Kp index is not more than 4 and the geomagnetic condition kept quiet relatively. As shown in Fig. 6 (a), there is a high-count area near the magnetic dip equator in South America, which shows the contamination in SAA associated with particles impacting the instrument. The example of global brightness of the $135.6 \mathrm{~nm}$ nightside channel without red-leak and the effect of dark count

155 is presented in Fig. 6 (b). As shown Fig. 6 (b), there are some brighter areas located oneither side of the magnetic dip equator in South America and Africa, which are the so-called equatorial ionization anomaly (EIA) structure. EIA has been 
(a)

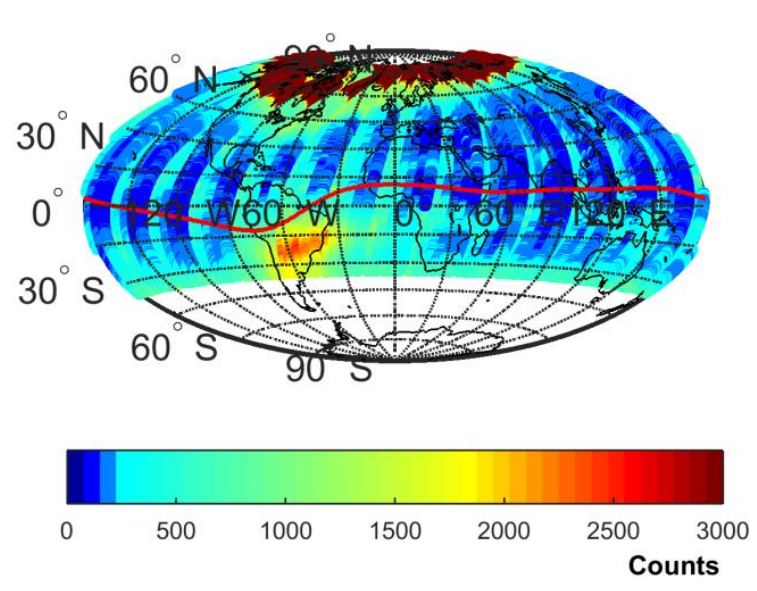

(b)

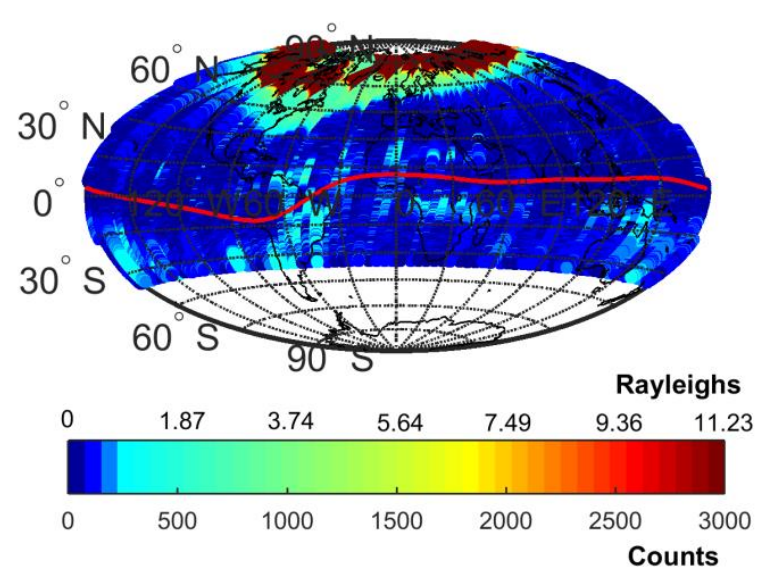

Figure 6: The global count (left) and brightness (right) of the 135.6nm nightside channel from 7 to 11 December 2017 . The brightness is without red-leak and the effect of dark count. The red solid line indicates the magnetic dip equator.

studied extensively by using data from ground-based ionosodes (Moffett and Hanson, 1965; Walker, 1981) and groundbased optical observations (Thuillier et al., 1976). The OI $135.6 \mathrm{~nm}$ emission data from GUVI on board TIMED satellite, FUV on board the IMAGE satellite, and the TIP on board the COSMIC satellites have been used in study of the EIA phenomenon (Christensen et al., 2003; Sagawa et al., 2005; Immel et al, 2006 and Coker et al., 2009). The local time of the IPM orbit on the nightside is 2:00 am. The EIA structure which we found at the 2:00 local time is later than other results mentioned earlier, and it need to be studied furtherly.

\section{2 $\mathrm{NmF}_{2}$ and TEC}

OI $135.6 \mathrm{~nm}$ emission is one of the strongest lines in the FUV nightglow at low latitudes and has relatively high transparency in the upper atmosphere. In the nightside ionosphere, there are two primary production mechanisms of OI $135.6 \mathrm{~nm}$ emission:

170 (1) Atomic oxygen is excited through the recombination of atomic oxygen ions with electrons and produces OI $135.6 \mathrm{~nm}$ emission; (2) Atomic oxygen is excited through the mutual neutralization of $\mathrm{O}^{+}$with $\mathrm{O}^{-}$and produces $\mathrm{OI} 135.6 \mathrm{~nm}$ emission (Meier, 1991). The mutual neutralization has a relatively smaller contribution. The brightness of OI $135.6 \mathrm{~nm}$ emission varies with the electron density and the oxygen ion concentration basically. Equivalently, OI $135.6 \mathrm{~nm}$ emission is approximately proportional to the square of the electron density in the F-region.

175 Based on the previous studies of the nighttime OI $135.6 \mathrm{~nm}$ airglow using the radiative and emissive model, IRl2000 model, and MSISE90 model, the retrieval algorithm of $\mathrm{NmF}_{2}$ derived from nighttime OI 135.6 nm emission was presented by Jiang et al. (2018). The brightness of the nighttime OI $135.6 \mathrm{~nm}$ emission is used to calculate ionospheric $\mathrm{NmF}_{2} \mathrm{by}$ the ratio 
between $\mathrm{NmF}_{2}$ and $\mathrm{OI} 135.6 \mathrm{~nm}$ emission from the retrieval algorithm. We selected the IPM derived $\mathrm{NmF}_{2}$ data which were near to four IGGCAS ionosonde stations(Sanya $\left(18.3^{\circ} \mathrm{N}, 109.6^{\circ} \mathrm{E}\right)$, Wuhan $\left(30.5^{\circ} \mathrm{N}, 114.4^{\circ} \mathrm{E}\right)$, Beijing $\left(40.3^{\circ} \mathrm{N}, 116.2^{\circ} \mathrm{E}\right)$, and Mohe $\left(50.2^{\circ} \mathrm{N}, 122.5^{\circ} \mathrm{E}\right)$ ) from November 25, 2017 to May 8, 2018. Their difference in longitude were less than $12^{\circ}$ and in latitude were less than $5^{\circ}$. There is a standard deviation of $26.67 \%$ between IPM $\mathrm{NmF}_{2}$ and IGGCAS ionosonde $\mathrm{NmF}_{2}$ (shown in Fig. 7).

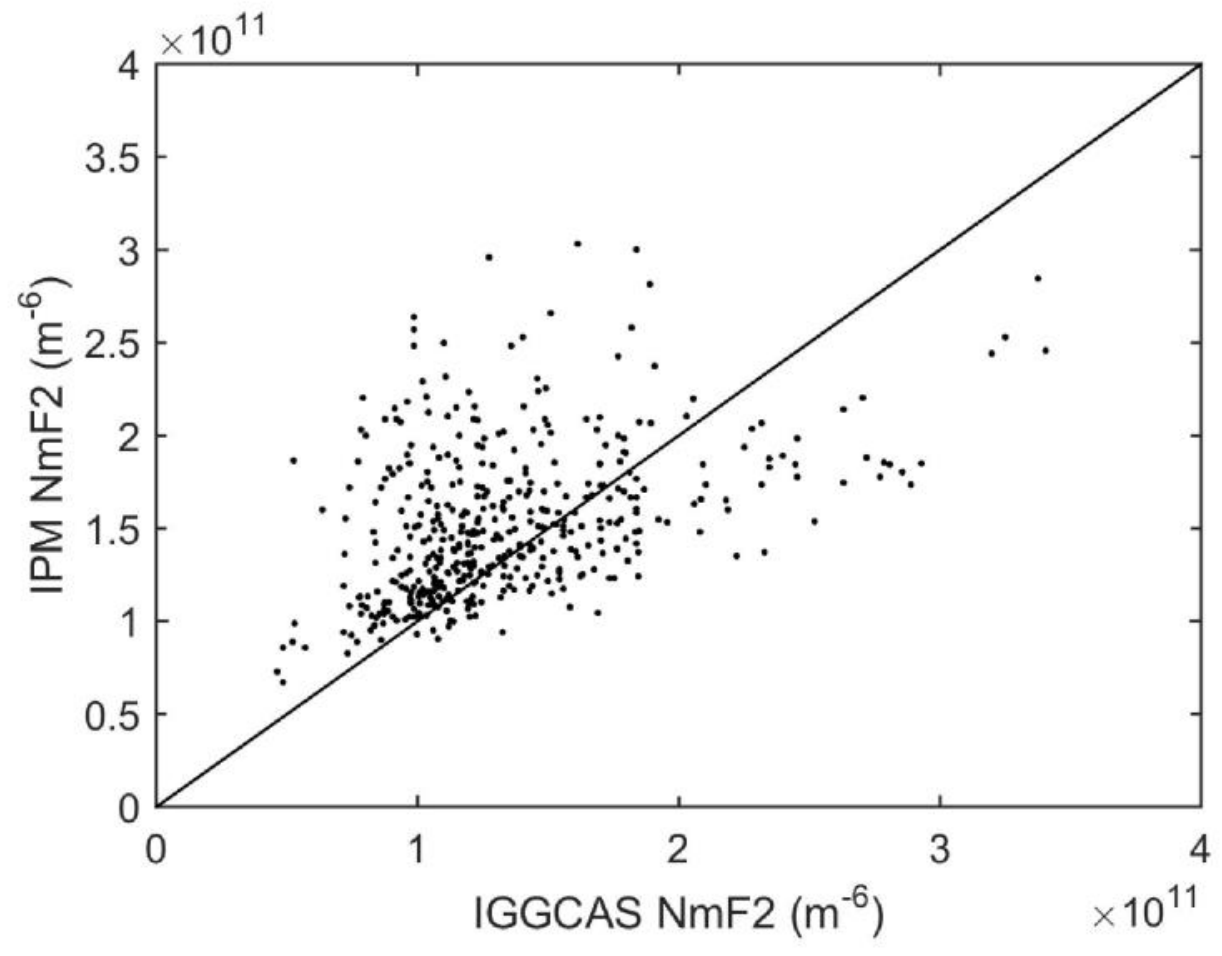

185 Figure 7: IPM derived NmF2 and IGGCAS ionosondes NmF2 from November 25, 2017 to May 8, 2018. (The longitude difference between the IPM substellar point and ionosonde stations is less than $12^{\circ}$, and the latitude difference is less than $5^{\circ}$. )

2014). We further calculated total electron content (TEC) from IPM results and compared with that of MIT TEC data from November 25, 2017 to April 8, 2018. The MIT TEC data (Rideout and Coster, 2006) was obtained from the MIT Haystack Observatory Madrigal database (http://www.openmadrigal.org). There is a standard deviation of 39.41\% between IPM TEC (total electron content unit, TECu) and MIT TEC (TECu) (shown in Fig.8). The standard deviation between IPM TEC $(\mathrm{TECu})$ and MIT TEC (TECu) is more than the one between IPM NmF 2 and IGGCAS ionosonde $\mathrm{NmF}_{2}$. In the Ionosphere plasmasphere coupled system, the ionosphere in conjugate hemispheres forms a plasmasphere reservoir along the interconnecting flux tube. There is diurnal interchange between the ionosphere and the plasmasphere that the downward diffusion from the plasmasphere helps to maintain the nighttime $\mathrm{F}_{2}$-layer. The results of Jason-1, Metop-A, and TerraSAR-X 
https://doi.org/10.5194/amt-2021-195

Preprint. Discussion started: 30 September 2021

(C) Author(s) 2021. CC BY 4.0 License.

(c) (i)

\section{Atmospheric \\ Measurement \\ Techniques \\ Discussions}

(Yizengawa et al., 2008; Zakharenkova and Cherniak, 2015; Klimenko et al., 2015) show that at day the contribution of the plasmasphere in TEC is less than the one of the ionosphere, whereas at night the contribution of the plasmasphere in TEC is increasing and even more than the one of the ionosphere.

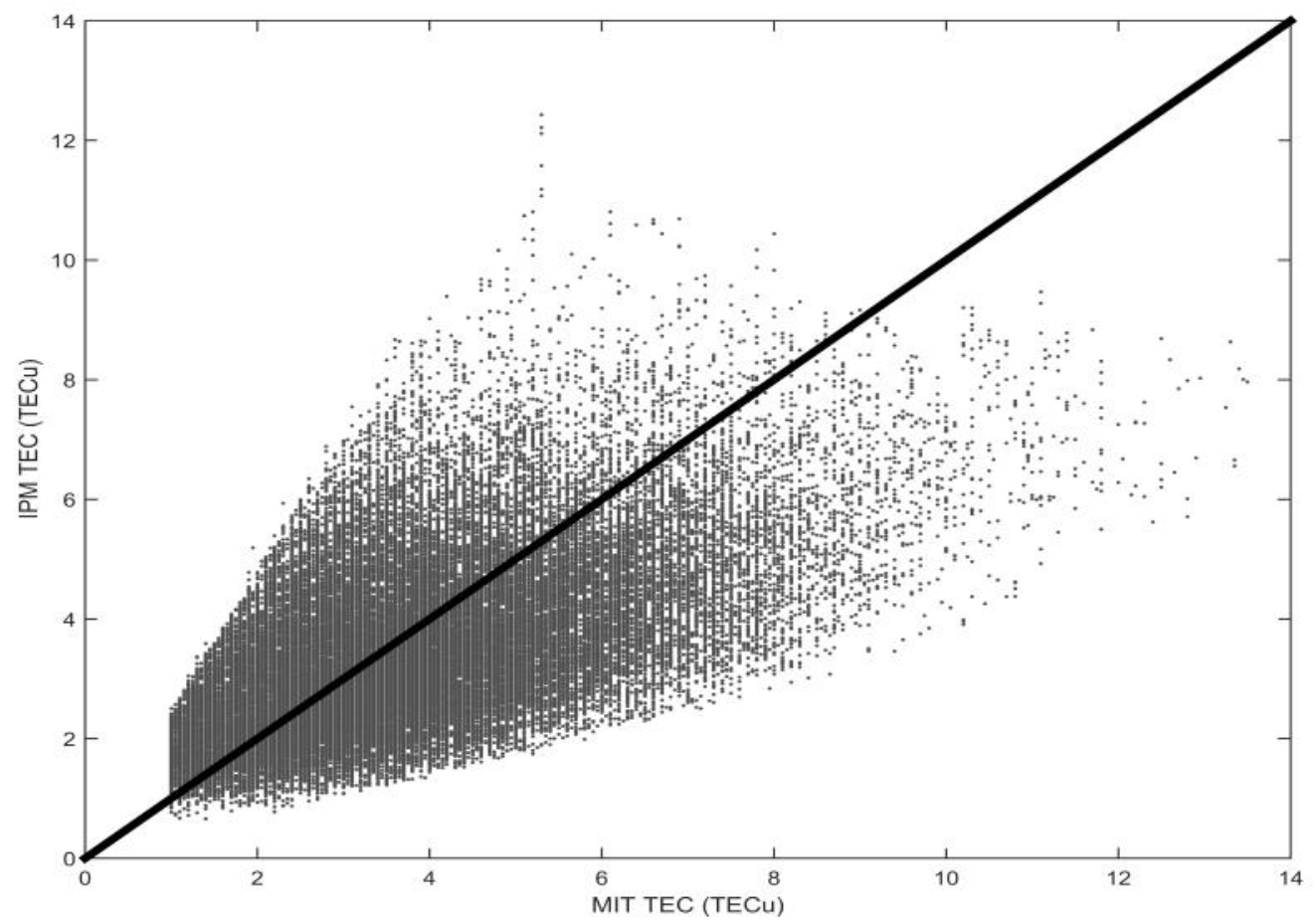

Figure 8: IPM TEC and MIT TEC (TECu) from November 25, 2017 to April 8, 2018

Auroral emission can be derived from the $135.6 \mathrm{~nm}$ nightside channel. There is obviously a strong auroral emission feature in the Northern Hemisphere in Fig. 6. By the way, the wide-field auroral imager (WAI), one of ten scientific instruments aboard the Feng Yun 3D meteorological satellite, has provided large field of view (FOV), high spatial resolution, and broadband ultraviolet images of the aurora (Zhang et al, 2019). 


\section{$3.3 \mathrm{O} / \mathrm{N}_{2}$}

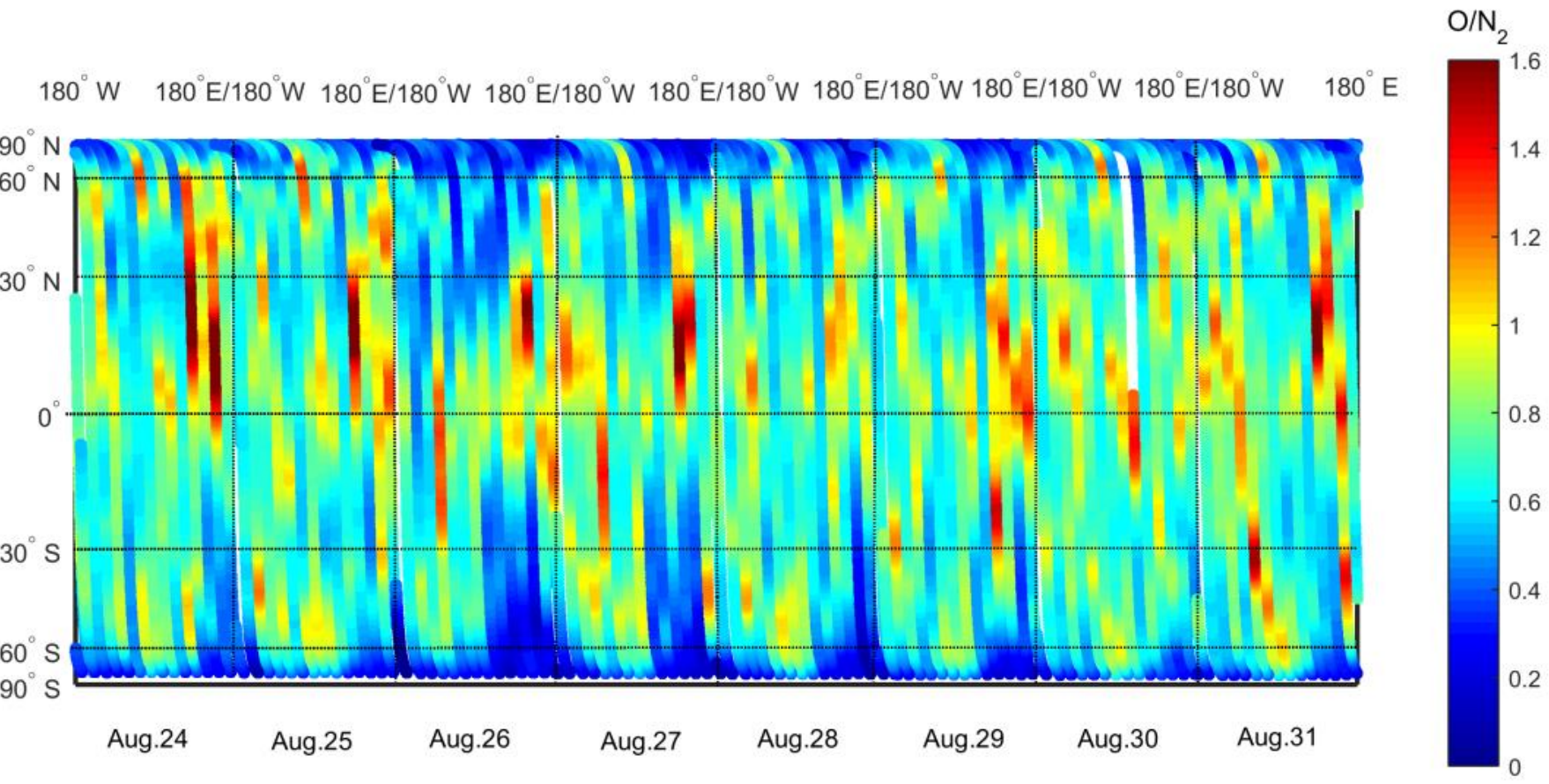

Figure 9: Column O/N2 around the magnetic storm of Aug.26, 2018.

210 Energetic photon-electron impact excitation of the neutral atmosphere produces $135.6 \mathrm{~nm}$ emission and $\mathrm{N}_{2} \mathrm{LBH}$ emission, which are proportional to the concentration of $\mathrm{O}$ and $\mathrm{N}_{2}$ respectively (Meier, 1991). $135.6 \mathrm{~nm}$ emission and $\mathrm{N}_{2} \mathrm{LBH}$ emission can be used to derive column $\mathrm{O} / \mathrm{N}_{2}$. The derivation of $\mathrm{O} / \mathrm{N}_{2}$ from disk 135.6 and $\mathrm{N}_{2} \mathrm{LBH}$ dayglow observations was first addressed by Strickland et al. (Strickland et al., 1995) And the topic of $\mathrm{O} / \mathrm{N}_{2}$ from $135.6 \mathrm{~nm}$ emission and $\mathrm{N}_{2} \mathrm{LBH}$ emission has been studied extensively (Christensen et al., 2014; Strickland et al., 2004; Zhang et al., 2014). During geomagnetic storms enhanced Joule and particle heating in the high latitude ionosphere produces upwelling of the oxygendepleted or nitrogen-rich air. The upwelling rises from much lower in the thermosphere into the F region. The heating also leads to enhanced horizontal equator-ward neutral winds that can change the distribution of the nitrogen-rich/oxygendepleted air.

The brightness of $135.6 \mathrm{~nm}$ emission on dayside can be derived from observations of the $135.6 \mathrm{~nm}$ dayside channel and the $\mathrm{N}_{2} \mathrm{LBH}$ dayside channel respectively. A Butterworth filter is used in data processing in order to deduct the red-leak from the cloud top. The simulation produced by the AURIC model (Wang and Wang, 2015) is used to obtain a lookup table that provides the coefficient of deriving $\mathrm{O} / \mathrm{N}_{2}$ from a measured pair of 135.6 and LBHS values. The result of column $\mathrm{O}$ and $\mathrm{N}_{2}$ ratio during the magnetic storm of Aug. 26, 2018 is presented in Fig. 9. On 24 August 2018 and most of 25 August 2018, Kp index is not more than 3. It abruptly rises 7 in 26 August 2018, descends and rises to 6 on 27 August 2018. From 29 to 31 
225 August 2018, Kp index is not more than 3. The column $\mathrm{O} / \mathrm{N}_{2}$ on 24 and 25 August is relatively quiet, and significant changes in column $\mathrm{O} / \mathrm{N}_{2}$ occur on 26 and 27 August. The reduction of $\mathrm{O} / \mathrm{N}_{2}$ extends from the high-latitude region to mid and low latitude regions in the Northern and Southern Hemisphere. On 30 and 31 August, column $\mathrm{O} / \mathrm{N}_{2}$ returns to the level before the magnetic storm.

\section{Conclusion}

230 The FY3D satellite was launched at 18:35 UTC on November 14, 2017 from the Taiyuan Satellite Base, Shanxi province, China. The Ionospheric Photometer instrument carried aboard the Feng Yun 3D meteorological satellite measures the spectral radiance of the Earth far ultraviolet airglow in the spectral region from 133 to $180 \mathrm{~nm}$. IPM is a tiny, highly sensitive, and robust remote sensing instrument. Preliminary observations show that the IPM could monitor the global structure of the equatorial ionization anomaly structure around 2:00 local time using OI $135.6 \mathrm{~nm}$ nightglow properly. It could also identify 235 the reduction of $\mathrm{O} / \mathrm{N}_{2}$ in the high-latitude region during the geomagnetic storm of Aug. 26, 2018. The IPM derived $\mathrm{NmF}_{2}$ accords well with that observed by 4 ionosonde stations along $120^{\circ} \mathrm{E}$ with a standard deviation of $26.67 \%$. Initial results demonstrate that the performance of IPM meets the designed requirement and therefore can be used to study the thermosphere and ionosphere in future.

Data availability. Data are available at http://satellite.nsmc.org.cn/PortalSite/Default.aspx.

Author contributions. Yungang Wang and Tian Mao performed the data validation and prepared the paper and most of the plots; Liping Fu and Fang Jiang designed IPM and provided laboratory calibration data; Xiuqing Hu, Chengbao Liu, Xiaoxin Zhang, Jiawei Li, Ling Sun, Zhongdong Yang, Peng Zhang and Jingsong Wang participated in instrument parameters

245 requirements, judging of instrument design and data validation; Zhipeng Ren, Fei He and Lingfeng Sun participated in validation and intercomparisons.

Competing interests. The authors declare that they have no conflict of interest.

250 Financial support. This research has been supported by the Natural Science Foundation of China under Grant 41874187, 41774195, and 41931073 and Fengyun Satellite Ground Application System.

\section{References}

Anthes, R. A., Bernhardt, P. A., Chen, Y., Cucurull, L., Dymond, K. F., Ector, D., Healy, S. B., Ho, S., Hunt D. C, Kuo, Y., 
https://doi.org/10.5194/amt-2021-195

Preprint. Discussion started: 30 September 2021

(c) Author(s) 2021. CC BY 4.0 License.
Atmospheric

Measurement

Techniques

Discussions

Liu, H., Maning, K., McCormick, C., Meehan, T. K., Randel, W J., Rocken, C., Schreiner, W S., Sokolovskiy, S. V., Syndergaard, S., Thompson, D, C., Trenberth, K.E., Wee, T., Yen, N. L., and Zeng, Z.: The COSMIC/FORMOSAT-3 mission: early results, Bull. Am. Meteor. Soc. vol.89, 313-333, doi:10.1175/BAMS-89-3-313 , 2008.

Budzien, S., Fritz, B., Stephan, A., Marquis, P., Powell, S., O’Hanlon, B., Nicholas, A., Dymond, K., and Brown, C.: Comparison of second and third generation $135.6 \mathrm{~nm}$ ionospheric photometers using onorbitand laboratory results, CubeSats and SmallSats for Remote Sensing III, International Society for Optics and Photonics, SPIE, 1-13, doi:10.1117/12.2528791, 2019.

Budzien, S., Powell, S., O’Hanlon, B., Bishop, R., Humphreys, T., Stephan, A.: Early Results and Ionospheric Observations from GROUP-C on the ISS, 15th International Ionospheric Effects Symposium, Alexandria, Virginia, Paper 11A3, 2017.

Christensen, A. B., Paxton, L. J., Avery, S., Craven, J., Crowley, G., Humm, D. C., Kill, H., Mejer, R. R., Meng, C., Morrison, D., Ogorzalek, B. S., Straus, P., Strickland, D. J., Swenson, R. M., Walterscheid, R. L., Wolven, B., and Zhang, Y.: Initial observations with the Global Ultraviolet Imager (GUVI) in the NASA TIMED satellite mission, J. Geophys. Res., vol.108, no.A12, 1-16, doi:10.1029/2003JA009918, 2003.

Coker, C., Dymond, K. F., Budzien, S. A., Chua, D. H., Liu, J., Anderson, D. N., Basu, S., and Pedersen, T. R.: Observations of the ionosphere using the tiny ionospheric photometer, Terr. Atmos. Ocean. Sci., vol.20, no.1, 227-235, doi:10.3319/TAO.2008.01.18.02 (F3C), 2009.

Dymond, K. F., Budzen, S. A., Coker, C., and Chua, D. H.: The Tiny Ionospheric Photometer (TIP) on the Constellation Observing System for Meteorology, Ionosphere, and Climate (COSMIC/FORMOSAT-3), J. Geophys. Res. Space Physics, vol.121, 10, 614-10,622, doi:10.1002/2016JA022900, 2016.

Dymond, K. F., Nicholas, A. C., Budzien, S. A., Stephan, A. W., Marquis, P., Brown, C. M., Finne, T., and Wolfram, K. D.:

275 Low-latitude ionospheric research using the CIRCE Mission: instrumentation overview, UV, X-Ray, and Gamma-Ray Space Instrumentation for Astronomy XX, Proc. SPIE 10397, 1039719, 2017.

Fu, L., Peng, R., Shi, E., Peng, J., Wang, T., Jiang, F., Jia, N., Li, X., and Wang, Y.: Far Ultraviolet nighttime ionospheric photometer, Astrophys Space Sci., vol.355, no.1, 1-7, doi: 10.1007/S10509-014-2139-9, 2015.

Jiang, F., Mao, T., and Fu, L.: The research on NmF2 and TEC derived from nighttime OI $135.6 \mathrm{~nm}$ emission measurement, Chinese J.Geophys. (in Chinese), vol.57, no.11, 3679-3687, doi:10.6038/cjg20141122, 2014.

Jiang, F., Mao, T., Li, X., Fu, L., Wang, Y., and Yu, T.: Retrieval algorithm and precision analysis for $\mathrm{NmF}_{2}$ of nighttime OI $135.6 \mathrm{~nm}$ emission, Chin. J. Space Sci., vol.38, no.1, 58-64, 2018.

Klimenko, M. V., Klimenko, V. V., Zakharenkova, I. E., and Cherniak L. V.: The global morphology of the plasmaspheric electron content during northern winter 2009 based on GPS/COSMIC observation and GSM TIP model results, Adv. Space Res., vol.55, no.8, 2077-2085, 2015.

Meier, R. R.: Ultraviolet spectroscopy and remote sensing of the upper atmosphere, Space Sci. Rev., vol.58, no.1, 1-185, doi:10.1007/BF01206000,1991. 
https://doi.org/10.5194/amt-2021-195

Preprint. Discussion started: 30 September 2021

(c) Author(s) 2021. CC BY 4.0 License.
Atmospheric

Measurement

Techniques

Discussions

Immel, T. J., Sagawa, E., England, S. L., Henderson, S. B., Hagan, M. E., Mende, S. B., Frey, H. U., Swenson C. M., and Paxton, L. J.: Control of equatorial ionospheric morphology by atmospheric tides, Geophys. Res. Lett., vol.33, L15108, 1-4, doi:10.1029/2006GL026161, 2006.

Moffett, R. J. and Hanson, W. B.: Effect of ionization transport on the equatorial F-region, Nature, vol.206, no.4985, 705706, 1965.

Paxton, L. J., Morrison, D., Strickland, D. J., McHarg, M. G., Zhang, Y.L., Wolven, B., Kill, H., Crowley, G., Christensen, A. B., and Meng, C.: The use of far ultraviolet remote sensing to monitor space weather, Adv. Space Res., vol.31, no.4, 813818, doi:10.1016/S0273-1177(02)00886-4, 2003.

Sagawa, E., Immel, T. J., Frey, H. U., and Mende, S. B.: Longitudinal structure of the equatorial anomaly in the nighttime ionosphere observed by IMAGE/FUV, J. Geophys. Res., vol.110, A11302, 1-10, doi:10.1029/2004JA010848, 2005.

Rideout, W., and Coster, A.: Automated GPS processing for global total electron content data, GPS Solutions, 10, 219-228, doi:10.1007/s10291-006-0029-5, 2006.

300 Stephan, A. W., Marquis, P. J., Budzien, S. A., Dymond, K. F., Brown, C. M., Wolfram, K. D., and Nicholas, A. C.: Evaluation of UV optics for Triple Tiny Ionospheric Photemeters on CubeSat missions: CubeSats and NanoSats for Remote Sensing, Proc. SPIE, 10769, 107690W, doi: 10.1117/12.2321042, 2018.

Strickland, D. J., Evans, J. S., and Paxton, L. J.: Satellite remote sensing of thermospheric O/N2 and solar EUV: 1, Theory, J. Geophys. Res., vol, 100, no.A7, 12217-12226, doi:10.1029/95JA00574, 1995.

305 Strickland, D. J., Meier, R. R., Walterscheid, R. L., Craven, J. D., Christensen, A. B., Paxton, L. J., Morrison, D., and Crowley, G.: Quiet-time seasonal behavior of the thermosphere seen in the far ultraviolet dayglow, J. Geophys. Res., vol. 109, doi:10.1029/2003JA010220, 2004.

Thuillier, G., King, J.W., and Slater, A. J.: An explanation of the longitudinal variation of the O1D (630 nm) tropical nightglow intensity, J. Atmos. Terr. Phys., vol.38, no.2, 155-158, 1976.

310 Walker, G.O.: Longitudinal structure of the F-region equatorial anomaly: a review, J. Atmos. Terr. Phys., vol.43, no.8, 763-774, doi: 10.1016/0021-9169(81)90052-0, 1981.

Wang, H. and Wang, Y.: Airglow simulation based on the atmospheric ultraviolet radiance integrated code of 2012, Science China: Earth Sciences, vol.45, 1768-1780, 2015.

Yizengawa, E.,Moldwin, M. B., Galvan, D., Lijima, B. A., Komjathy, A., and Mannucci, A. J.: Global plasmaspheric TEC 315 and its relative contribution to GPS TEC, J. Atmos. Terr. Phys., vol.70, 1541-1548, doi:10.1016/j.jastp.2008.04.022, 2008. Zakharenkova, I. and Cherniak, L.: How can GOCE and TerraSAR-X contribute to the topside ionosphere and plasmasphere research, Space Weather, vol.13, 271-285, doi:10.1002/2015SW001162, 2015.

Zhang, X., Chen, B., He, F., Song, K., He, L., Liu, S., Guo, Q., Li, J., Wang, X., Zhang, H., Wang, H., Han, Z., Sun, L., Zhang, P., Dai, S., Ding, G., Chen, L., Wang, Z., Shi, G., Yu, C., Yang, Z., Zhang, P., and Wang, J.: Wide-field auroral 320 imager onboard the Fengyun satellite, Light: Science \& Applications, vol.8, no.47, 1:12, doi:10.1038/s41377-019-0157-7, 2019. 
https://doi.org/10.5194/amt-2021-195

Preprint. Discussion started: 30 September 2021

(c) Author(s) 2021. CC BY 4.0 License.

(c) (i)

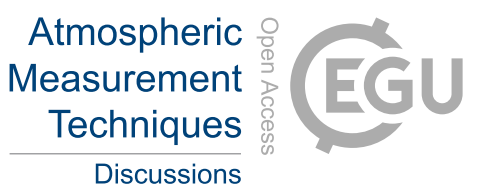

Zhang, Y., Paxton, L. J., Morrison, D., Marsh, D., and Kil, H: Storm-time behaviors of O/N 2 and NO variations, J. Atmos.

Terr. Phys., vol.114, 42-49, doi:10.1016/j.jastp.2014.04.003, 2014. 